\title{
The thermal evolution of Mars as constrained by paleo-heat flows
}

\author{
Javier Ruiz ${ }^{\mathrm{a}, *}$, Patrick J. McGovern ${ }^{\mathrm{b}}$, Alberto Jiménez-Díaz ${ }^{\mathrm{a}}$, Valle López ${ }^{\mathrm{c}, \mathrm{d}}$, Jean-Pierre Williams ${ }^{\mathrm{e}}$, \\ Brian C. Hahn ${ }^{\mathrm{f}}$, Rosa Tejero ${ }^{\mathrm{a}, \mathrm{d}}$ \\ ${ }^{a}$ Departamento de Geodinámica, Facultad de Ciencias Geológicas, Universidad Complutense de Madrid, 28040 Madrid, Spain \\ ${ }^{\mathrm{b}}$ Lunar and Planetary Institute, 3600 Bay Area Boulevard, Houston, TX 77058, USA \\ 'Instituto de Geología Económica, CSIC-UCM, 28040 Madrid, Spain \\ "Instituto de Geociencias, CSIC-UCM, 28040 Madrid, Spain \\ - Department of Earth and Space Sciences, University of California, Los Angeles, CA 90095, USA \\ Department of Earth and Pianetary Sciences, University of Tennessee, Knoxville, IN 37996, USA
}

Keywords:

Mars

Mars, Interior

Thermal histories

\begin{abstract}
A B S T R A C T
Lithospheric strength can be used to estimate the heat flow at the time when a given region was deformed, allowing us to constrain the thermal evolution of a planetary body. In this sense, the high $(>300 \mathrm{~km}$ ) effective elastic thickness of the lithosphere deduced from the very limited deflection caused by the north polar cap of Mars indicates a low surface heat flow for this region at the present time, a finding difficult to reconcile with thermal history models. This has started a debate on the current heat flow of Mars and the implications for the thermal evolution of the planet. Here we perform refined estimates of paleo-heat flow for 22 martian regions of different periods and geological context, derived from the effective elastic thickness of the lithosphere or from faulting depth beneath large thrust faults, by considering regional radioactive element abundances and realistic thermal conductivities for the crust and mantle lithosphere. For the calculations based on the effective elastic thickness of the lithosphere we also consider the respective contributions of crust and mantle lithosphere to the total lithospheric strength. The obtained surface heat flows are in general lower than the equivalent radioactive heat production of Mars at the corresponding times, suggesting a limited contribution from secular cooling to the heat flow during the majority of the history of Mars. This is contrary to the predictions from the majority of thermal history models, but is consistent with evidence suggesting a currently fluid core, limited secular contraction for Mars, and recent extensive volcanism. Moreover, the interior of Mars could even have been heating up during part of the thermal history of the planet.
\end{abstract}

\section{Introduction}

A very interesting and productive debate on the present-day heat flow and thermal state of Mars, and their implications for the thermal evolution of the planet, is currently occurring (Phillips et al., 2008; Kiefer and Li, 2009; Grott and Breuer, 2009, 2010; Ruiz et al., 2010; Dombard and Phillips, 2010). The very high (>300 km) effective elastic thickness of the lithosphere implied by the very limited (if any) deflection caused by the loading due to the north polar cap of Mars (Phillips et al., 2008) indicates a low surface heat flow at the present-time that is difficult to reconcile with most thermal history models. This low heat flow could be indicative of sub-chondritic heat-producing elements abundances (Phillips et al., 2008), a limited influence of secular cooling and fossil heat
(Ruiz et al., 2010), or simply a regional variability of surface heat flow (Phillips et al., 2008; Kiefer and Li, 2009; Grott and Breuer, 2009, 2010). This debate clearly shows the profound implications that current or ancient surface heat flow estimates, deduced from geological or geophysical indicators of the thermal state of the lithosphere, have for understanding the thermal history of Mars.

Previous works estimated surface heat flows for diverse regions and epochs of Mars from the effective elastic thickness of the lithosphere (Solomon and Head, 1990; Anderson and Grimm, 1998; Zuber et al., 2000; Nimmo, 2002; Kiefer, 2004; McGovern et al., 2002, 2004; Grott et al., 2005; Ruiz et al., 2006a,b, 2008, 2010; Kronberg et al., 2007; Ruiz, 2009; Dohm et al., 2009a; Ritzer and Hauck, 2009) or from the depth to the brittle-ductile transition (BDT) beneath large thrust faults (Schultz and Watters, 2001; Grott et al., 2007; Ruiz et al., 2008, 2009); such heat flow estimates correspond to the time when the lithosphere was loaded or faulted. These previous works find a general decrease of heat flows with time, as expected for a cooling planet (McGovern et al., 2002, 2004; Montesi and Zuber, 2003), although there were some 
indications of regional variations in surface heat flows since comparatively higher heat flows are found for volcanic regions (McGovern et al., 2004).

However, the values of material parameters used to derive heat flow estimates varies widely, limiting the ability to integrate the results of different studies to collectively constrain the thermal history of Mars. Specifically, the amount and distribution of lithospheric heat-producing elements (HPE) and the values of the thermal conductivity of crust and mantle can affect the results substantially (Ruiz et al., 2006a, 2010). Heat flow estimates typically have not included HPE in the calculations: this omission reduces the calculated surface heat flow but increases calculated mantle heat flow and temperatures in the lower crust. Similarly, most workers used a very high mantle lithosphere thermal conductivity, which overestimates the surface heat flow for high effective elastic thicknesses but underestimates temperatures in the mantle lithosphere.

In this work we carefully calculate in a consistent manner paleo-heat flow for 22 martian regions of different ages and geological contexts (Fig. 1). We improve the heat flow calculations by taking into account realistic thermal conductivities for the crust and mantle lithosphere (including a temperature-dependent thermal conductivity, appropriate for olivine, for the mantle lithosphere), and two extreme cases for the abundance and distribution of HPE: we use refined HPE values based on Mars Odyssey GRS measurement and zero lithospheric HPE to calculate upper and lower limits, respectively, for the surface heat flows. For the heat flow calculations that use the effective elastic thickness of the lithosphere we also consider the respective contributions of crust and mantle components to the total strength of the lithosphere. Finally, we compare our results with estimates of radioactive heat production deduced from compositional models and with predictions from thermal history models, in order to obtain constrains on the thermal evolution of Mars. Since heat flow upper limits are more useful to constrain thermal evolution, we have been very careful to provide very robust upper limit calculations for the analyzed regions.

\section{Strength of the lithosphere}

The effective elastic thickness is a measure of the total strength of the lithosphere, integrating contributions from brittle and ductile layers and from elastic cores of the lithosphere (for a review see Watts and Burov (2003)). Effective elastic thickness estimates can be converted to estimates of heat flow following the equivalent strength envelope procedure described by McNutt (1984). This methodology is based on the condition that the bending moment $M$ of the mechanical lithosphere must be equal to the bending moment of the equivalent elastic layer of thickness $T_{e}$, and so,

$\frac{E K T_{e}^{3}}{12\left(1-v^{2}\right)}=\int_{0}^{T_{m}} \sigma(z)\left(z-z_{n}\right) d z$

where $E$ is the Young's modulus, $K$ is the topography curvature, $T_{e}$ is the effective elastic thickness, $v$ is the Poisson's ratio, $T_{m}$ is the mechanical thickness of the lithosphere, $\sigma(z)$ is the least, at depth $z$, of the brittle strength, the ductile strength, or the fiber stress due to plate flexure, and $z_{n}$ is the depth to the neutral stress plane. Additionally, the condition of zero net axial force is imposed,

$\int_{0}^{T_{m}} \sigma(z) d z=0$

The case of a rheologically stratified lithosphere with mechanically decoupled crust and mantle is more complicated (see, for example, McNutt et al., 1988; Burov and Diament, 1992; Ruiz et al., 2006c), and the total bending moment is given by

$M=M_{\text {crist }}+M_{\text {mantle }}$,

where the subindex refers to the crust and mantle lithosphere contributions to the total bending moment. Also, in this case the condition of zero net axial force must be imposed on both the crust and lithospheric mantle.

The brittle strength is calculated according to the expression (e.g., Ranalli, 1997)

$\left(\sigma_{1}-\sigma_{3}\right)_{b}=\alpha \rho g(1-\lambda) z$

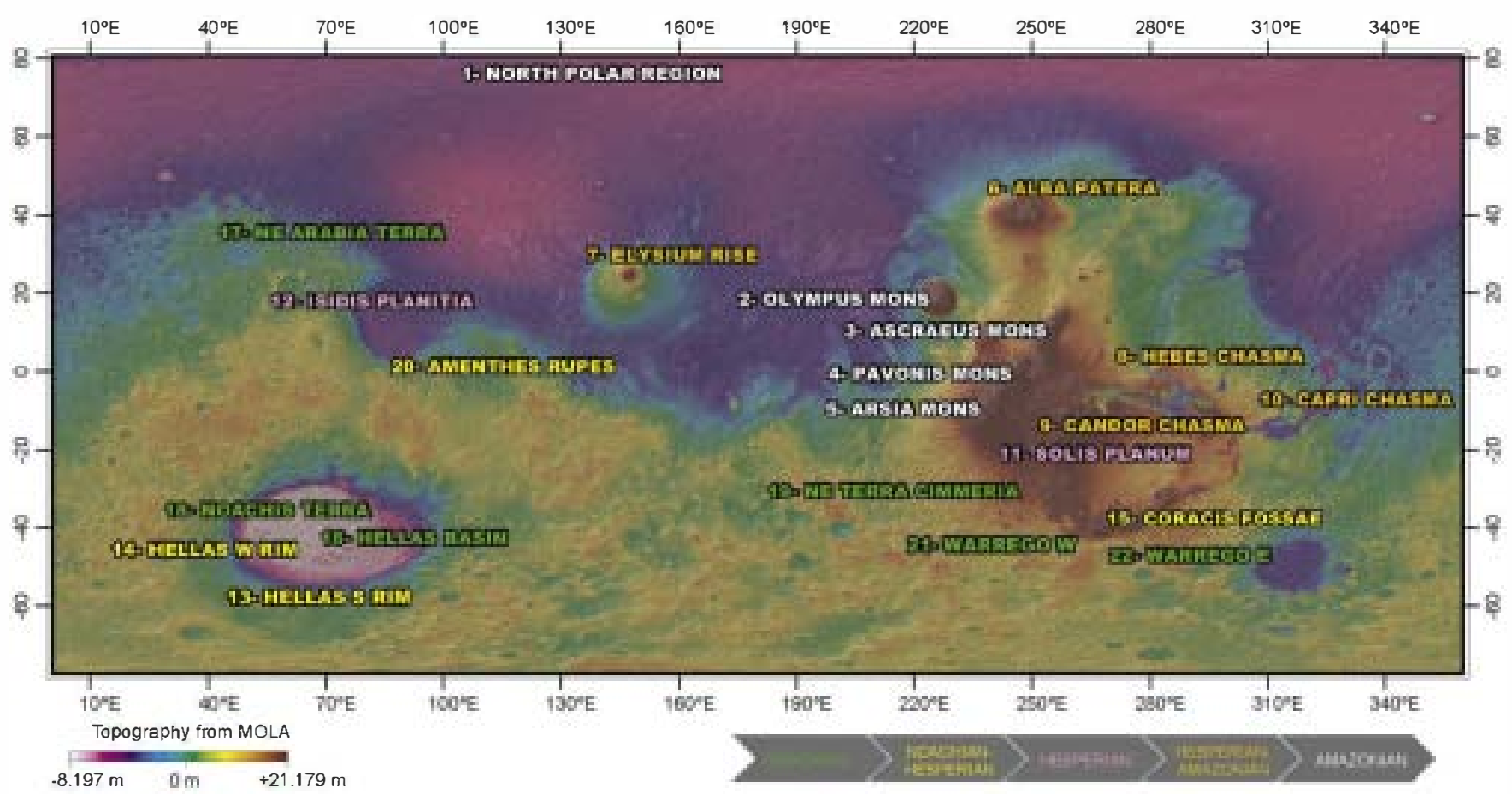

Fig. 1. MOLA topography map showing the analyzed regions. 
where $\alpha$ is a coefficient depending on the stress regime (which is 3 and 0.75 for pure compression and tension respectively; e.g., Ranalli, 1997), $\rho$ is the density, $g$ is the acceleration due to the gravity ( $3.72 \mathrm{~m} \mathrm{~s}^{-2}$ for Mars), $\lambda$ is the pore pressure, and $z$ is the depth. The brittle strength of the crust is here calculated directly from Eq. (4) by using the density of the crust. The brittle strength of the lithospheric mantle is calculated for a density of $3500 \mathrm{~kg} \mathrm{~m}^{-3}$ and starting from the brittle strength at the base of the crust. The ductile strength (which does not depend on the stress regime) is given by

$\left(\sigma_{1}-\sigma_{3}\right)_{d}=\left(\frac{\dot{e}}{A}\right)^{1 / n} \exp \left(\frac{Q}{n R T}\right)$

where $\dot{e}$ is the strain rate, $A, Q$, and $n$ are laboratory-determined constants, $R\left(=8.31447 \mathrm{~J} \mathrm{~mol}^{-1} \mathrm{~K}^{-1}\right)$ is the gas constant, and $T$ is the absolute temperature. The fiber stress is in turn calculated from

$\sigma_{f i b}=\frac{E K\left(z-z_{n}\right)}{1-v^{2}}$.

The link between the strength envelope procedure and heat flow comes from the dependence of the ductile strength on temperature.

We analyze regions for which estimates of effective elastic thickness and topography curvatures of the equivalent elastic layer are available (see Table 1). Also, the elastic parameters in these estimates must be consistent with the nominal values of $E=100 \mathrm{GPa}$ and $v=0.25$, which are widely used for Mars (e.g., McGovern et al., 2002; Phillips et al., 2008). The density of the crust is taken as $2900 \mathrm{~kg} \mathrm{~m}^{-3}$, unless a different value has been inferred from geophysical modeling (e.g., McGovern et al., 2004) for a given region, and the mantle lithosphere density is taken as $3500 \mathrm{~kg} \mathrm{~m}^{-3}$. The admittance modeling of McGovern et al. (2004), from which derive the majority of effective elastic thicknesses in Table 1, was performed for a mean crustal thickness of $50 \mathrm{~km}$, whereas the crustal thickness maps of Neumann et al. $(2004,2008)$ were constructed for a mean crustal thickness of $45 \mathrm{~km}$. Thus, for our calculations we assume local crustal thicknesses based on regional trends in Neumann et al. (2008) but increased by $5 \mathrm{~km}$, in order to be consistent with the mean value of McGovern et al. (2004). Positive and negative topography curvatures are concave downward and upward, respectively, which implies that the part of the elastic plate above the neutral stress plane is under tension or compression, respectively (e.g., Turcotte and Schubert, 2002). This determines the value of the parameter $\alpha$ used for each case in Eq. (4). For several regions in Table $1 T_{e}$ upper (lower) limits are unavailable; for these regions we cannot obtain lower (upper) limits for the heat flow.

We perform calculations for zero pore pressure and hydrostatic pore pressure. Increasing the pore pressure decreases the total strength of the lithosphere, and the heat flow must be lowered in order to maintain the total strength consistent with a given $T_{e}$. Thus, for equal $T_{e}$, zero and hydrostatic pore pressures serve to place upper and lower limits, respectively, to the obtained surface heat flow.

For creep parameters of the martian crust we use the constants for the flow law of diabase: $A=0.0612 \mathrm{MPa}^{-n} \mathrm{~s}^{-1}, n=3.05$ and $\mathrm{Q}=276 \mathrm{~kJ} \mathrm{~mol}^{-1}$ (Caristan, 1982). The use of a wet diabase law is appropriate for a basaltic martian crust and is consistent with extensive evidence for water-related geological activity in early Mars (e.g., Head et al., 2001; Dohm et al., 2009b); moreover, the water amount needed to "wet" the diabase is certainly modest (lower than 1\%; see Caristan, 1982). The ductile strength of the mantle lithosphere is calculated for dry and wet olivine dislocation creep rheologies, which give upper and lower limits, respectively, to the surface heat flow. For wet olivine, we use the flow law of the Anita Bay dunite: $A=9550 \mathrm{MPa}^{-n} \mathrm{~s}^{-1}, n=3.35$ and $\mathrm{Q}=444 \mathrm{~kJ} \mathrm{~mol}^{-1}$ (Chopra and Paterson, 1984). This flow law places a lower limit on the strength of wet olivine due to its relative weakness (compared with other wet dunites, such as Aheim dunite). For dry olivine we use the flow law obtained for artificially dried dunites (which is valid for both Anita Bay and Aheim dunites): $A=28840 \mathrm{MPa}^{-n} \mathrm{~s}^{-1}, n=3.6$ and $\mathrm{Q}=535 \mathrm{~kJ} \mathrm{~mol}^{-1}$ (Chopra and Paterson, 1984). Zhao et al. (2009) have recently reported that

Table 1

Values used for the calculation of heat flows from the effective elastic thickness $\left(T_{e}\right)$ of the lithosphere.

\begin{tabular}{|c|c|c|c|c|c|c|}
\hline Feature & Centered on & Surface age & $T_{e}(\mathrm{~km})$ & Curvature $\left(10{ }^{7} \mathrm{~m}^{1}\right)^{\mathrm{h}}$ & Crustal density $\left(\mathrm{kg} \mathrm{m}^{3}\right)$ & Crustal thickness $(\mathrm{km})$ \\
\hline 1. North Pole ${ }^{a}$ & $90^{\bullet} \mathrm{N}, 0^{\bullet} \mathrm{E}$ & Current & $>300$ & 0 & 2900 & 30 \\
\hline 2. Olympus Mons ${ }^{\mathrm{b}}$ & $19^{\bullet} \mathrm{N}, 226.5^{\circ} \mathrm{E}$ & A & $>70$ & -1.6 & 2900 & 55 \\
\hline 3. Ascraeus Mons ${ }^{b}$ & $11.5^{\circ} \mathrm{N}, 2^{\circ} 6^{\circ} \mathrm{E}$ & A & $\leqslant 80^{\xi}$ & -0.69 & 2900 & 70 \\
\hline 4. Pavonis Mons ${ }^{\mathrm{b}}$ & $0.5^{\bullet} \mathrm{N}, 247^{\circ} \mathrm{E}$ & A & $<100$ & -1.0 & 2900 & 75 \\
\hline 5. Arsia Mons ${ }^{b}$ & $g^{\bullet} \mathrm{S}, 239^{\bullet} \mathrm{E}$ & A & $>20$ & -13 & 2900 & 85 \\
\hline 6. Alba Patera ${ }^{\mathrm{b}}$ & $42^{\bullet} \mathrm{N}, 249^{\bullet} \mathrm{E}$ & $\mathrm{A}-\mathrm{H}$ & $38-65$ & -1.8 to -0.55 & 2900 & 65 \\
\hline 7. Elysium rise ${ }^{b}$ & $25^{\bullet} \mathrm{N}, 147^{\bullet} \mathrm{E}$ & $\mathrm{A}-\mathrm{H}$ & $15-45$ & -9.9 to -2.3 & 2900 & 45 \\
\hline 8. Hebes Chasma ${ }^{\mathrm{b}}, \mathrm{c}$ & $1 \bullet S, 284^{\bullet} \mathrm{E}$ & $\mathrm{A}-\mathrm{H}$ & $\geqslant 60$ & -1.2 & 2900 & 65 \\
\hline 9. Candor Chasmab, & $8^{\bullet} \mathrm{S}, 295^{\circ} \mathrm{E}$ & $\mathrm{A}-\mathrm{H}$ & $\geqslant 80$ & -1.2 & 2200 & 70 \\
\hline 10. Capri Chasma ${ }^{\mathrm{b}, \mathrm{c}}$ & $12^{\bullet} \mathrm{S}, 310^{\bullet} \mathrm{E}$ & $\mathrm{A}-\mathrm{H}$ & $>100$ & -0.6 & 2500 & 55 \\
\hline 11. Solis Planum ${ }^{\mathrm{b}}$ & $25^{\circ} \mathrm{S}, 270^{\circ} \mathrm{E}$ & $\mathrm{H}$ & $24-37$ & +6.4 to +3.0 & 2900 & 70 \\
\hline 12. lsidis Planitia ${ }^{d}$ & $13^{\bullet} \mathrm{N}, 8^{\bullet} \mathrm{E}$ & $\mathrm{H}$ & $100-180$ & -0.09 to -0.02 & 2900 & 10 \\
\hline 13. Hellas $S$ rim $^{\mathrm{b}}$ & $64^{\circ} \mathrm{S}, 66^{\circ} \mathrm{E}$ & $\mathrm{H}-\mathrm{N}$ & $20-120$ & +6.4 to +0.34 & 2900 & 55 \\
\hline 14. Hellas $W$ rim $^{b}$ & $42^{\bullet} \mathrm{S}, 39^{\circ} \mathrm{E}$ & $\mathrm{H}-\mathrm{N}$ & $<20$ & -3.9 & 2650 & 55 \\
\hline 15. Coracis Fossae & $34.5^{\circ} \mathrm{S}, 274.5^{\circ} \mathrm{E}$ & $\mathrm{H}-\mathrm{N}^{\mathrm{I}}$ & $10.3-12.5$ & +6.4 to +4.9 & 2900 & 75 \\
\hline 16. Hellas Basin ${ }^{\mathrm{b}}$ & $42^{\bullet} \mathrm{S}, 66^{\bullet} \mathrm{E}$ & $\mathrm{N}$ & $<13$ & -7.6 & 2750 & 15 \\
\hline 17. NE Arabia Terrab & $36^{\bullet} \mathrm{N}, 40^{\circ} \mathrm{E}$ & $\mathrm{N}$ & $<16$ & -2.4 & 2500 & 50 \\
\hline 18. Noachis Terrab & $35^{\bullet} \mathrm{S}, 26^{\bullet} \mathrm{E}$ & $\mathrm{N}$ & $<12$ & -3.1 & 2800 & 65 \\
\hline 19. Terra Cimmeria ${ }^{b}$ & $30^{\circ} \mathrm{S}, 180^{\circ} \mathrm{E}$ & $\mathrm{N}$ & $<12$ & -4.2 & 2950 & 60 \\
\hline
\end{tabular}

Phillips et al. (2008)

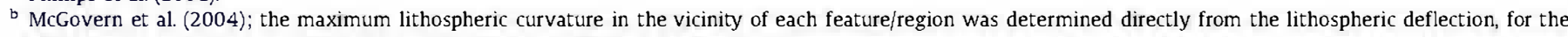
models that correspond to the upper and/or lower bounds on effective elastic thickness.

c There are alternative best fit $T_{e}$ values (McGovern et al., 2004), but we use values maximizing the heat flow range.

d Ritzer and Hauck (2009).

Grott et al. (2005)

A surface age of 3.5-3.9 Ga has been reported for this feature by Grott et al. (2005).

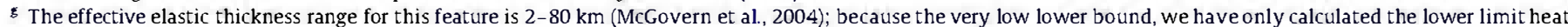
flows for this feature.

${ }^{\mathrm{h}}$ Curvature values correspond to the quoted $T_{e}$ values; positive and negative values indicate, respectively, concave upward and downward curvatures. 
anhydrous olivine is considerably weaker when it is proportionally iron-rich, as expected for the martian mantle, which would reduce mantle strength and hence the obtained heat flows. Thus, the use of rheology of Chopra and Paterson (1984) provides a generous upper limit for heat flows obtained from lithospheric strength. (There are not similar published experiments for iron-rich wet olivine.) Strain rates of $10^{-16}$ and $10^{-19} \mathrm{~s}^{-1}$ are used in the calculations, based on the range usually considered for Mars (McGovern et al., 2002, 2004). To make a comparison, terrestrial strain rates are typically $\sim 10^{-16} \mathrm{~s}^{-1}$ in active continental interiors (e.g., Tesauro et al., 2007), and $\sim 10^{-19}-10^{-17} \mathrm{~s}^{-1}$ in stable plate interiors (Kumar and Gordon, 2009).

The base of the mechanical lithosphere is here defined as the depth at which the ductile strength reaches a low value of $10 \mathrm{MPa}$ (see Ranalli, 1994; Ruiz et al., 2006a), and below which there are no further significant increases in strength, although varying the exact value selected does not produce substantial changes in the calculations due to the exponential dependence of ductile strength on temperature (see McNutt, 1984).

The depth of the brittle-ductile transition (BDT) can also be used in order to calculate surface heat flows (Ruiz and Tejero, 2000). This depth can be deduced by estimating the depth of faults that are thought to extend down until the crustal BDT, and hence the temperature at the BDT depth is obtained by equating the brittle and ductile strength for the depth $z=z_{B D T}$,

$T_{B \boldsymbol{D T}}=\frac{\mathrm{Q}}{R}\left[\ln \frac{A\left(\sigma_{1}-\sigma_{3}\right)_{B D T}^{n}}{\dot{e}}\right]^{-1}$,

where $\left(\sigma_{1}-\sigma_{3}\right)_{B D T}$ is the strength at the BDT depth from Eq. (4). The heat flow is then obtained by matching $T_{B D T}$ to a temperature profile. Here we use this procedure for three prominent lobate scarps (Table 2), interpreted to be the surface expression of large thrust faults. It must be noted that pore fluid pressure reduces brittle strength, and hence increases temperature at the BDT depth. Thus, upper and lower limits for the surface heat flow are calculated, respectively, for hydrostatic conditions and zero pore pressure, the opposite to the case for calculations based on the effective elastic thickness of the lithosphere.

\section{Temperature profiles}

Surface heat flows obtained from lithospheric strength are higher, for a fixed $T_{e}$ or BDT depth, if lithospheric radioactive heat sources are included in the calculations than if purely thermal gradients are used (see Ruiz et al., 2006a, 2008, 2009). Thus, we calculate surface heat flow upper limits by including HPE in the crust and the mantle lithosphere, whereas lower limits are obtained by using zero lithospheric heat sources.

The significant homogeneity of elemental abundances measure by Mars Odyssey GRS suggests that the martian crust is much less geochemically varied than the Earth's crust (Taylor et al., 2006), which is consistent with a strong mixing by cratering (e.g. Taylor et al., 2006), and with the absence of large-scale crustal recycling, at least since the early part of the history of Mars (e.g., Frey, 2006).
Indeed, some authors have suggested that Mars experienced an early phase of plate tectonics (e.g., Sleep, 1994; Baker et al., 2007), although high-resolution topography and radar sounding have revealed a large population of buried impact basins on Mars, implying a similar, and very early ( $>4 \mathrm{Ga}$ ), age of the basement throughout the entire planet (Frey, 2006; Watters et al., 2006). Temperature profiles in the crust are therefore calculated by assuming a homogeneous distribution of radioactive heat sources. Although it is possible that crustal HPE abundances decrease with depth, a homogeneous distribution gives higher surface heat flow and therefore is useful for our upper limit calculations. Also, we use a constant thermal conductivity for the crust, and therefore the temperature at a given depth $z$ is given by

$T_{z}=T_{s}+\frac{F z}{k_{c}}-\frac{\rho_{c} H_{c} z^{2}}{2 k_{c}}$

where $T_{s}$ is the surface temperature, $F$ is the surface heat flow, $k_{c}$ is the thermal conductivity of the crust, $\boldsymbol{\rho}_{c}$ is the density of the crust, and $H_{c}$ is the crustal heat production rate per unit mass. We use a surface temperature of $220 \mathrm{~K}$, the present-day mean surface temperature on Mars (Kieffer et al., 1977), which is consistent with the inference of low near-surface temperatures deduced for most of the past $4 \mathrm{Ga}$ from ALH84001 thermochronology (Shuster and Weiss, 2005). Also, we use $k_{c}=2 \mathrm{~W} \mathrm{~m}^{-1} \mathrm{~K}^{-1}$, a value appropriate for intact basaltic rocks; this value is in the uppermost part of the range for intact (non-porous) basalts (see the compilation by Beardsmore and cull (2001)).

Crustal potassium and thorium abundances for each analyzed region (Table 3 ) have been obtained from $5^{\circ} \times 5^{\circ}$ pixel maps of GRS abundances renormalized considering the volatile content, in order to reflect a volatile/alteration-free composition, more likely to be representative of the total crust, and not surface contamination (Hahn et al., 2011). Uranium abundances are estimated using a $\mathrm{Th} / \mathrm{U}$ ratio of 3.8. Potassium and thorium abundance values of the pixels corresponding to the analyzed features are good regional approximations due to the regional scale of the GRS footprint; the footprint of the GRS instrument from which 50\% of the gamma ray signal originates is between 480 and $600 \mathrm{~km}$ in diameter (roughly $8-10^{\circ}$ measured at the equator) depending upon energy (e.g., Boynton et al., 2007). For the North Polar Region, where GRS measurements are absent, we use global averages. For Hellas south rim, for which there are potassium and thorium GRS measurements but no volatile values, we use the same volatile abundances as for Hellas west rim. Heat dissipation rates are calculated for decay constants from Van Schmus (1995), and regional ages are listed in Table 1. The effective elastic thicknesses from the admittance study of McGovern et al. (2004) were estimated for regions including surfaces of different epochs (see also Tanaka, 1986). For these regions we use the age range embracing the appropriate periods. Absolute ages for period boundaries are derived from the cratering chronologies of Hartmann and Neukum (2001); when Hartmann's and Neukum's chronologies differ (for the Late Hesperian epoch or younger) we use the mean value as representative.

Table 2

Values used for the calculation of heat flows from the brittle-ductile transition (BDT) depth.

\begin{tabular}{|c|c|c|c|c|c|}
\hline Feature & Centered on & Surface age & BDT depth $(\mathrm{km})$ & Crustal density $\left(\mathrm{kg} \mathrm{m}^{3}\right)$ & Crustal thickness $(\mathrm{km})$ \\
\hline 20. Amenthes Rupes ${ }^{a}$ & $2^{\bullet} \mathrm{N}, 249^{\bullet} \mathrm{E}$ & $\mathrm{H}-\mathrm{N}$ & $27-35$ & 2900 & 50 \\
\hline 21. Warrego $\mathrm{W}^{\mathrm{b}}$ & $41^{\circ} \mathrm{S}, 263^{\circ} \mathrm{E}$ & $N^{c}$ & $27-35$ & 2900 & 80 \\
\hline 22. Warrego $\mathrm{E}^{\mathrm{b}}$ & $43^{\circ} \mathrm{S}, 267^{\bullet} \mathrm{E}$ & $\mathrm{N}^{\mathrm{c}}$ & $21-28$ & 2900 & 75 \\
\hline
\end{tabular}

a Ruiz et al. (2008)

b Grott et al. (2005)

c A surface age of 3.7-4.0 Ga has been reported Grott et al. (2005) for this feature. 
Table 3

Heat-producing element abundances.

\begin{tabular}{llll}
\hline Feature & $\mathrm{K}(\mathrm{ppm})$ & $\mathrm{Th}(\mathrm{ppm})$ & $\mathrm{U}(\mathrm{ppm})$ \\
\hline 1. North Pole & $3652^{\mathrm{a}}$ & $0.69^{\mathrm{a}}$ & $0.18^{\mathrm{a}}$ \\
2. Olympus Mons & 3390 & 0.63 & 0.17 \\
3. Ascraeus Mons & 3220 & 0.67 & 0.18 \\
4. Pavonis Mons & 3540 & 0.68 & 0.18 \\
5. Arsia Mons & 3630 & 0.63 & 0.17 \\
6. Alba Patera & 3070 & 0.51 & 0.13 \\
7. Elysium rise & 2900 & 0.53 & 0.14 \\
8. Hebes Chasma & 3670 & 0.54 & 0.14 \\
9. Candor Chasma & 3850 & 0.54 & 0.14 \\
10. Capri Chasma & 4310 & 0.65 & 0.17 \\
11. Solis Planum & 2540 & 0.42 & 0.11 \\
12. Isidis Planitia & 4590 & 0.86 & 0.23 \\
13. Hellas S rim & 2850 & 0.36 & 0.10 \\
14. Hellas W rim & 3750 & 0.77 & 0.20 \\
15. Hellas Basin & 3030 & 0.36 & 0.09 \\
16. Coracis Fossae & 2960 & 0.51 & 0.13 \\
17. NE Arabia Terra & 3640 & 0.79 & 0.21 \\
18. Noachis Terra & 3850 & 0.75 & 0.20 \\
19. Terra Cimmeria & 4830 & 0.97 & 0.26 \\
20. Amenthes Rupesa & 3540 & 0.68 & 0.18 \\
21. Warregow & 3100 & 0.60 & 0.16 \\
22. Warrego E & 3260 & 0.57 & 0.15 \\
\hline
\end{tabular}

Average values for the martian crust.

The thermal conductivity of olivine (the main mineral in the mantle) is strongly temperature-dependent, and therefore we calculate temperature profiles in the mantle lithosphere from

$\frac{d T}{d z}=\frac{F_{c b}-\rho_{m} H_{m}\left(z-b_{c}\right)}{k_{m}(T)}$,

where $F_{c b}=F-\rho_{c} H_{c} b_{c}$ is the heat flow at the base of the crust, $m$ and $H_{m}$ are, respectively, the density and heat production rate per mass unity of the mantle lithosphere, $b_{c}$ is the base of the crust, and $k_{m}$ is the thermal conductivity of the mantle lithosphere. The value of $H_{m}$ is poorly constrained, and here we use $H_{m}=0.1 H_{c(\alpha v) \text {. }}$ where $H_{c(a v)}$ is the average value for the martian crust. This choice is based on a ratio between crustal and primitive mantle HPE abundances higher than 10 for Mars (Taylor and McLennan, 2009), and represents a reasonable upper limit for $H_{m}$ (melt extraction would reduce mantle HPE abundances), which in turn results in an upper limit to the obtained surface heat flow (the lower limit is obtained for $H_{c}=0$ and $H_{m}=0$ ).

For $k_{m}$ we use the thermal conductivity of olivine, the main mineral in lithospheric mantle rocks, according to the expression (McKenzie et al., 2005)

$k_{m}=\frac{a}{1+c(T-273)}+\sum_{i=0}^{3} d_{i} T^{i}$

where $a=5.3, c=0.0015, d_{0}=1.753 \times 10^{-2}, d_{1}=-1.0364 \times 10^{-4}$, $d_{2}=2.2451 \times 10^{-7}$ and $d_{3}=-3.4071 \times 10^{-11}$, for calculating an upper limit for the thermal conductivity of olivine as a function of temperature. Results obtained from Eq. (10) are similar to those of Hofmeister (1999) for forsterite olivine. The thermal conductivity of some silicate minerals somewhat decreases with the increasing of the proportion of iron (Hofmeister, 1999). The martian mantle is considered to be iron-rich (e.g., Halliday et al., 2001), and for this reason Eq. (10) gives an upper limit to the thermal conductivity of the mantle lithosphere of Mars. However, there are not, to our knowledge, similar expressions to Eq. (10) accounting for iron content of olivine. Eq. (10) applied to the martian mantle lithosphere would overestimate the thermal conductivity (by less than $1 \mathrm{~W} \mathrm{~m}^{-1} \mathrm{~K}^{-1}$ ), which is useful for calculation of surface heat flow upper limits; on the other hand, for the calculation of surface heat flow lower limits this effect is balanced by the assumption of zero lithospheric heat sources.

For the case of the North Polar Region we additionally consider the effect of the polar cap above (but not included in) the lithosphere. The polar cap is assumed to be composed of water-ice. The thermal conductivity of cold water-ice is high, and the presence of rocks or other ices (e.g., $\mathrm{CO}_{2}$ ) would reduce the bulk thermal conductivity, and hence the calculated heat flow. For this reason, non-water-ice components are not taken into account in our upper-limit calculation. The thermal conductivity of waterice is strongly temperature-dependent, and therefore the temperature profile in the polar cap is given by

$T_{p c b}=T_{s} \exp \left(\frac{F b_{p c}}{k_{0}}\right)$

where $T_{s}$ is the surface temperature, $F$ is the surface heat flow (equal to the heat flow reaching the polar cap from below), $b_{p c}$ is the thickness of the polar cap, and $k_{0}=621 \mathrm{~W} \mathrm{~m}^{-1}$ (Petrenko and Whitworth, 1999). Here we use $T_{s}=155 \mathrm{~K}$ and $b_{p c}=2 \mathrm{~km}$ as representative of the martian polar regions (Plaut et al., 2007; Phillips et al., 2008; Wieczorek, 2008).

\section{Results}

Surface heat flows are calculated by constructing thermal profiles (Section 3) that satisfy the constraints imposed by indicators of lithospheric strength (Section 2). Calculations based on faulting depth only consider the thermal structure of the crust above the BDT depth, since the lithosphere below it does not influence the results. Calculations based on the effective elastic thickness of the lithosphere consider the entire thickness of the mechanical lithosphere. Also, the condition of non-negative sublithospheric heat flow is imposed for calculations using lithospheric heat sources. A negative sublithospheric heat flow could occur if assumed lithospheric HPE abundances are higher than the actual ones for a particular region (for example, the crust could be stratified, with a HPE-poor lower crust; see Ruiz et al., 2006b, 2009). If the sublithospheric heat flow is negative, then the thermal profile is adjusted to enforce zero sublithospheric heat flow and permit a ductile strength higher than $10 \mathrm{MPa}$ at the base of the mechanical lithosphere. This is appropriate for calculating a generous upper limit to the surface heat flow since, as above noted, higher lithospheric strength increases the surface heat flow for a given $T_{e}$.

Results are shown in Fig. 2 as a function of age. Fig. 2 also shows the average surface heat flow corresponding to the total radioactive heat production of Mars after the compositional model of Wänke and Dreibus (1988). From Fig. 2 it is evident that most of the estimated heat flow upper limits, and all the lower limits, are below the radioactive heat flow curve (although lower limits from features for which an upper limit is not available give a limited constraint on the thermal history). Also, the obtained heat flows are lower than predicted for the majority of thermal history models of Mars (e.g., Hauck and Phillips, 2002; Williams and Nimmo, 2004; Grott and Breuer, 2010; Fraeman and Korenaga, 2010).

Our results can also be interpreted in terms of the Urey number $U r$, the ratio of the internal heat production to the total surface heat loss in a planet. Fig. 2 indicates very low heat flows relative to expected heat output, consistent with very little secular cooling, i.e., a bulk-Mars Urfor Mars approaching 1.0 or perhaps even exceeding that value. Current estimates of the bulk-Earth Ur are in the range 0.35-0.53 (e.g., Jaupart et al., 2007; Korenaga, 2008), and somewhat higher (but usually $<0.75$ ) values are predicted for most martian thermal history models (see Fig. 3).

If $U r>1$ the martian interior (as an average) would be heating up. For illustrative purposes, we have estimated the mantle 


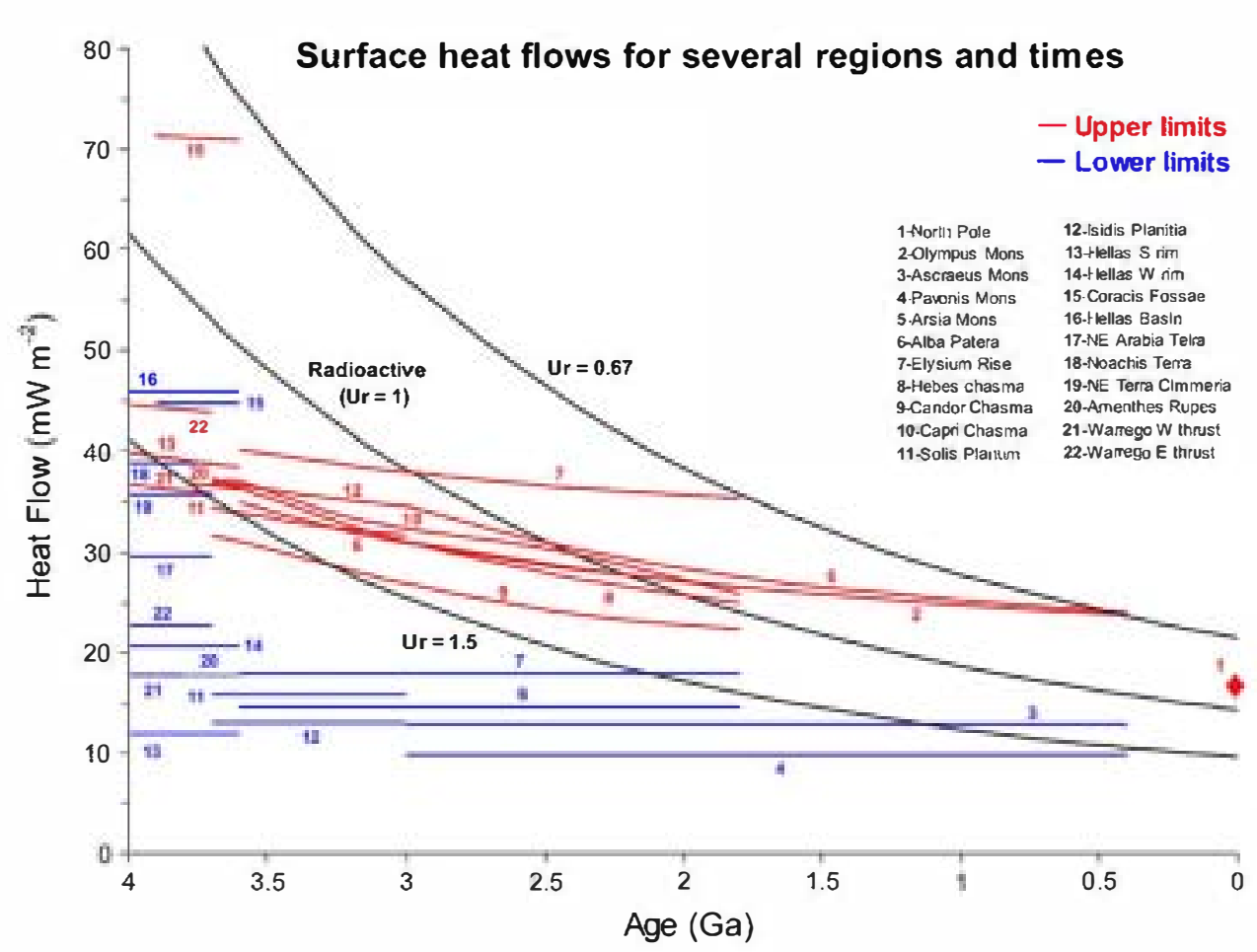

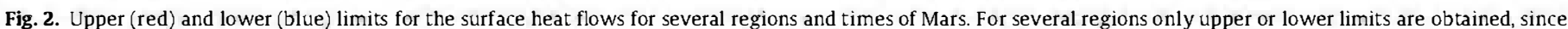

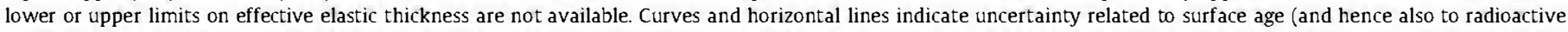

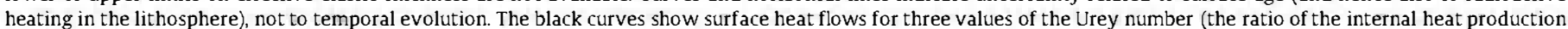

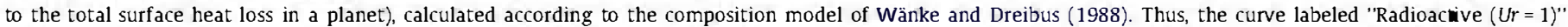

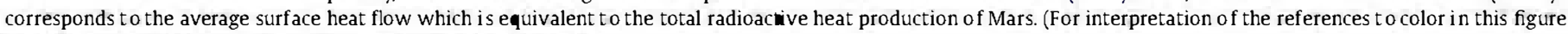
legend, the reader is referred to the web version of this article.)

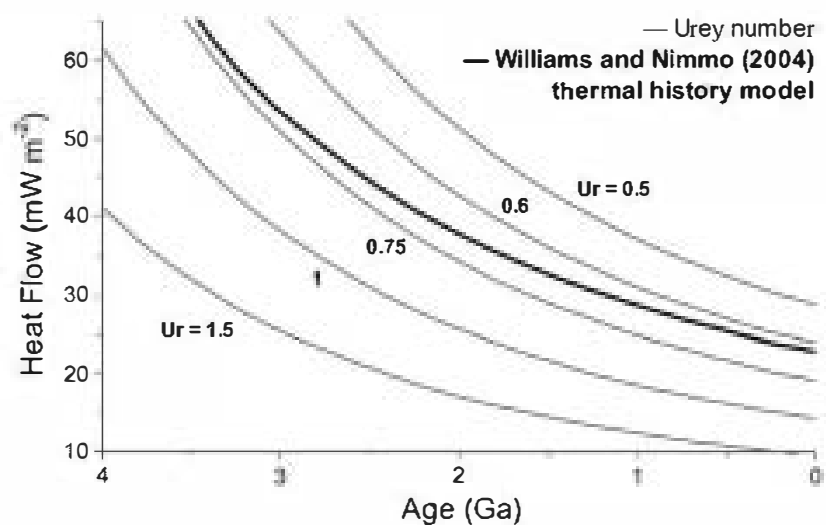

Fig. 3. Heat flows as a function of age and Urey number compared with the predictions of a thermal history model of Mars (calculated according to Williams and Nimmo (2004)), which obtain results similar to those of other thermal history models for Mars (e.g., Hauck and Phillips, 2002; Grott and Breuer, 2010). The Urey number is between 0.75 and 0.6 through the entire history of Mars.

temperature change for constant representative values for the Urey number by integrating the mantle heat balance equation from McGovern and Schubert (1989) using martian interior heat production values deduced from the HPE abundances of Wänke and Dreibus (1988). We obtain mantle temperature increases of 160 and $320 \mathrm{~K}$ for, respectively, Urey numbers of 1.2 and 1.5 integrated over the entire history of Mars. These values would be in any case generous upper limits given that the time period for which Ur could have been higher than 1 is likely to be significantly less than 4.6 Gyr. Under appropriate conditions ( $U r>1$ and surface heat flow higher than the radioactive contribution from the lithosphere), heating of the convective mantle and cooling (and thickening) of the lithosphere could simultaneously occur.

Fig. 4 shows upper limits to the surface heat flow as a function of feature age and type of terrain (Fig. 5 shows the location, period and relative value of these upper limits). The only terrains for which surface heat flow could clearly exceed the equivalent radioactive heat flow are volcanic regions (Coracis Fossae is a rift zone with associated magmatism; Dohm et al., 2001; Grott et al., 2005), although uncertainties in feature age and effective elastic thickness preclude a definitive conclusion. Also, regional heat flow variations related to differences in crustal HPE abundances and/or crustal thickness (which influences the total amount of crustal HPE in the lithospheric column), are also expected (e.g., Grott and Breuer, 2010; Hahn et al., 2011), although our results lack the resolution to reveal these variations.

The estimates of effective elastic thickness for Isidis Planitia are comparatively high (Ritzer and Hauck, 2009), but the obtained surface heat flow is similar to other regions due to the very low curvatures and thin crust (which increases the mantle contribution to the total strength of the lithosphere) in this region. Similarly, the very high lower limits of the effective elastic thickness estimated for the North Polar Region (Phillips et al., 2008) gives a heat flow upper limit slightly higher than the equivalent radioactive heat flow due to the absence of flexure (and also to a relatively thin crust) in this region. On the other hand, the heat flow lower limits obtained for non-volcanic Noachian terrains (for which only upper limits are available for the effective elastic thickness) do not rule out a very high surface heat flow when the large-scale topography of these regions was formed. However, the absence of upper limit estimates for the surface heat flow in these regions greatly diminishes their relevance as constraints on the thermal evolution of Mars. 


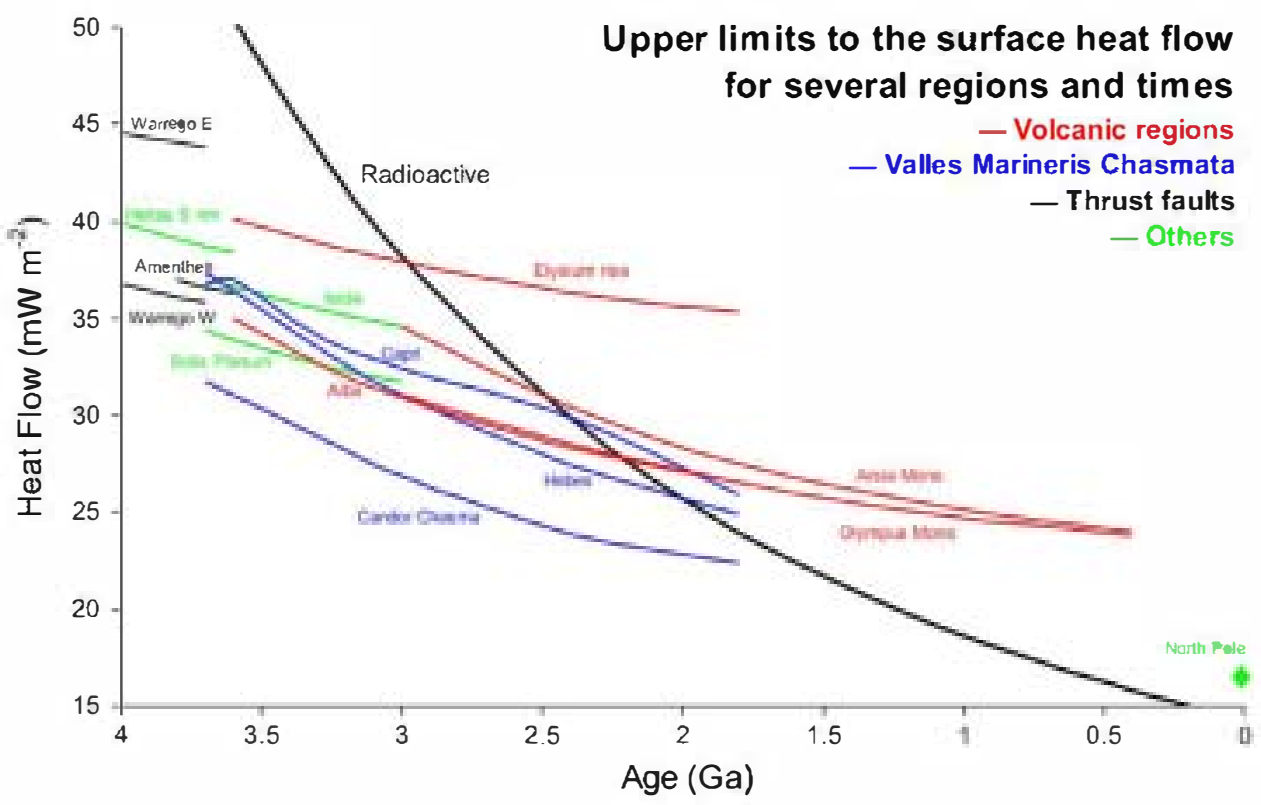

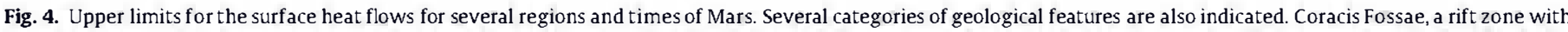

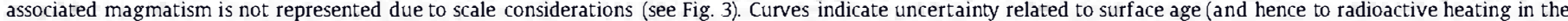

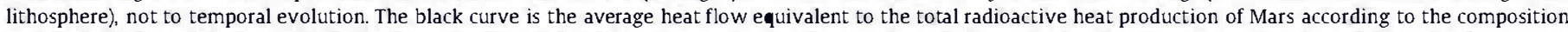
model of Wänke and Dreibus (1988). (For interpretation of the references to color in this figure legend, the reader is referred to the web version of this article.)

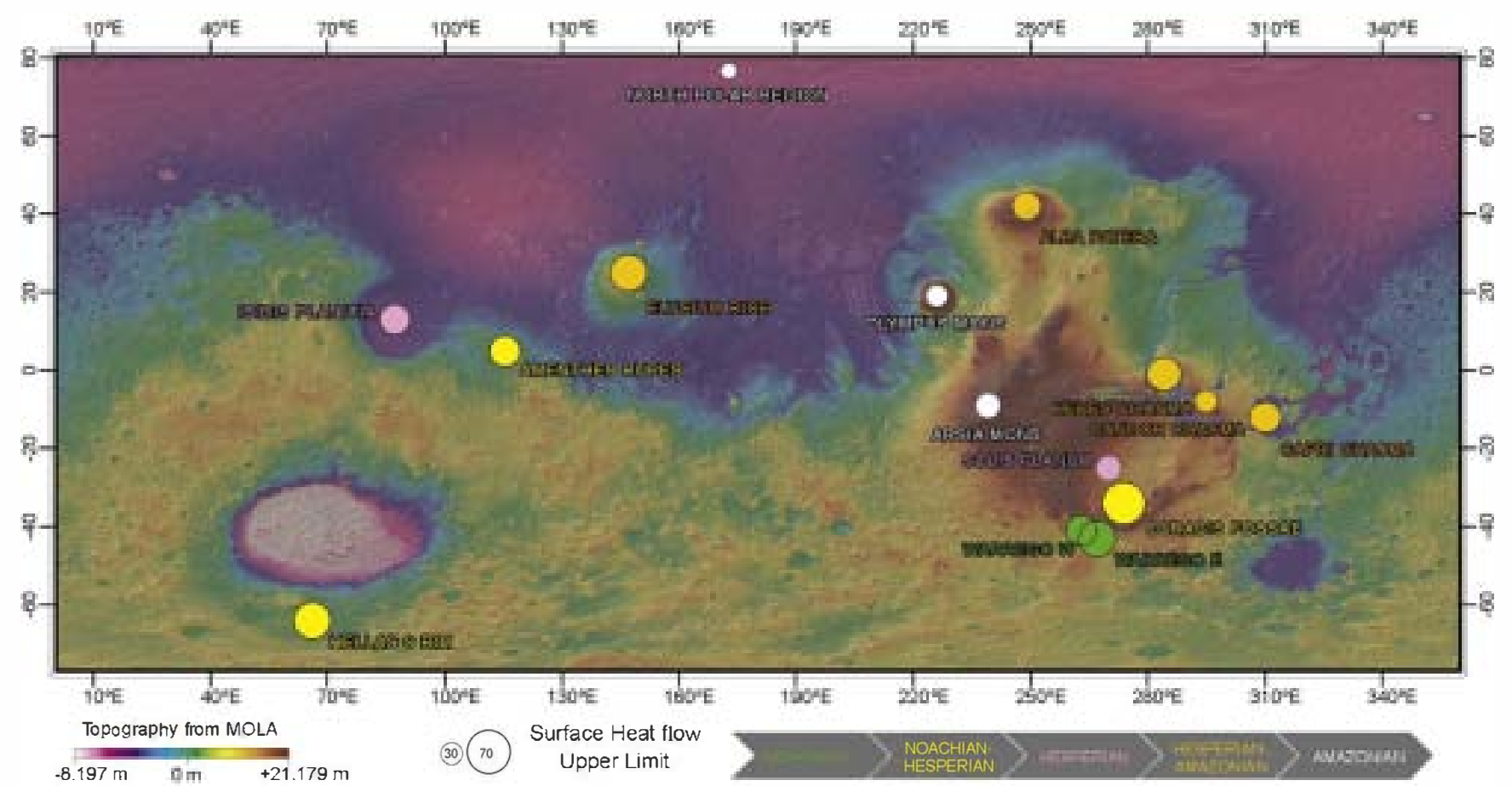

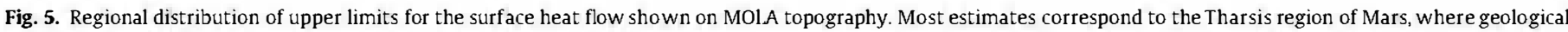
activity is concenwated.

\section{Discussion}

Our results indicate that the contribution from secular cooling to the surface heat flow has been limited during the majority of the history of Mars, contrary to the predictions of most thermal history models (e.g., Hauck and Phillips, 2002; Grott and Breuer, 2010). Further, the heat flow estimates in Fig. 2 suggest that the martian mantle was heating up during a significant fraction of the history of the planet (at least during Hesperian and Early Amazonian periods). These results are robust due to the conservative assumptions applied in generating our heat flow upper bounds.

Fig. 6 shows upper limits for sublithospheric heat flows (in essence the heat flow from the convective mantle), calculated in the same way as upper limits in Figs. 2 and 4 except by assuming $H_{c}=0$ and $H_{m}=0$ : in absence of lithospheric heat sources the surface heat flow equals the sublithospheric heat flow. Calculated 


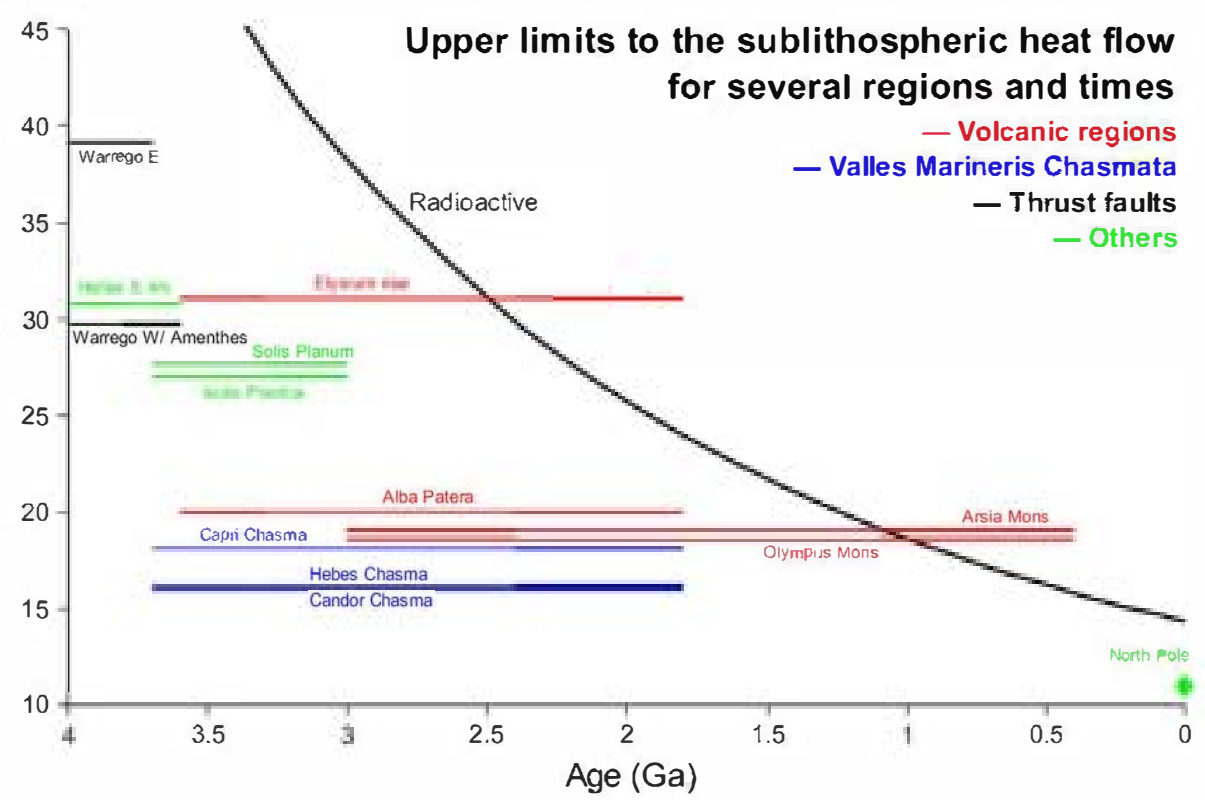

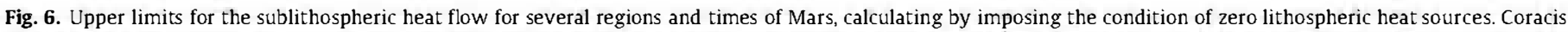

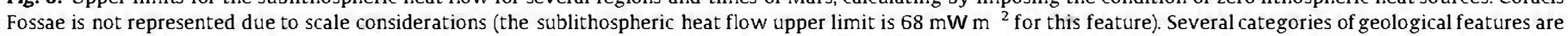
also indicated. Black curve as in Fig. 4. (For interpretation of the references to color in this figure legend, the reader is referred to the web version of this article.)

upper limits for sublithospheric heat flows are again lower than predicted from the majority of thermal history models (e.g., Hauck and Phillips, 2002; Grott and Breuer, 2010). These low sublithospheric heat flow values also suggest that mantle convection has been less efficient than has been appreciated in many studies of martian thermal evolution.

Our results are consistent with several independent geophysical and geological observations. For example, high mantle temperatures reduce core cooling, possibly contributing to the presentday existence of $a$, at least partly, fluid core (deduced from the response to the solar tide; Yoder et al., 2003), and to the simultaneous absence of an endogenic magnetic field (e.g., Acuña et al., 2001) due to the reduction (or even suppression) of core convection (e.g., Nimmo and Stevenson, 2000). Our results are also consistent with a lower amount of global contraction since the Early Noachian than expected from thermal history models, as deduced from thrust faults recorded on the surface (Nahm and Schultz, 2011); indeed, the lack of mantle cooling (and maybe mantle heating) limits the thermal contraction that can drive surface contraction. Finally, the evidences for recent extensive volcanism (Hauber et al., 2011) also suggest the retention of a substantial amount of internal heat.

Our results are also supported by parameterized mantle convection models that couple convective vigor with the rheologic weakening effect of interior volatiles suggesting that high Urey ratios are also favored by inefficient cycling of volatiles to and from the mantle (McGovern and Schubert, 1989; Sandu et al., 2011), as might be expected for Mars, which has lacked a plate tectonic cycle to efficiently degas and (especially) replenish the mantle volatiles at least since the early part of the evolution of Mars. Further, High Urey ratios might typify all planets lacking the thermal efficiency of plate tectonics.

Alternatively, a substantial amount of heat could be transported by hydrothermal cooling of the upper crust (Parmentier and Zuber, 2007). However, hydrothermal circulation could only operate above the brittle-ductile transition, since below porosity is mostly eliminated by viscous creep (Hanna and Phillips, 2005). This implies that, for a given temperature at the BDT, the obtained temperature profile below the BDT depth (and the sublithospheric heat flow) is the same if hydrothermal cooling is occurring or not (although in our calculations surface heat flows are increased with respect to the value at the BDT depth due to radioactive heating in the brittle crust). Magmatic activity could enhance hydrothermal circulation and heat flow on space scales lower than resolved by admittance studies, but to justify in this way average heat flows higher than those obtained here for the majority of the history and regions of Mars seems unrealistic.

On the other hand, Baratoux et al. (2011a,b) have recently modeled melting pressures and degrees of partial melting from GRS data for 12 Hesperian and Amazonian volcanic provinces, and hence potential mantle temperatures and (using linear thermal gradients and a constant thermal conductivity for the entire lithosphere) heat flows, suggesting bulk-Mars Ur 0.6-0.7 or lower, in accordance with most thermal history models. However, volcanic regions are expected to be associated with higher than average heat flows (see Figs. 2 and 4), making any Urvalue based on those regions a lower limit. Thus, the melting pressures and degrees of partial melting obtained by Baratoux et al. (2011a,b) do not alter our conclusions.

\section{Conclusions}

Our results strongly suggest that Mars has been losing less heat than conventionally thought during, at least, a substantial part of its history. This would be indicative of less efficient mantle convection than commonly thought (perhaps related to stagnant lid convection with inefficient volatile cycling) and/or a reduced contribution from fossil heat to the surface heat flow, which would result in a lower heat flow from the convective mantle, and possibly elevated lower mantle and core temperatures. Also, there is evidence favoring a heterogeneous heat flow depending on the geological province (volcanic versus non-volcanic provinces), although it cannot presently be definitively demonstrated. Moreover, if the interior of Mars is in fact heating up (Ur>1), there is the potential for a future increase in mantle convective vigor and/or melting, and there may ultimately be a resurgence of volcanic and tectonic activity. 
It is clear that a better understanding of the thermal evolution of Mars requires a feedback between thermal history models and heat flow calculations based on the evolution of the strength of the lithosphere.

\section{Acknowledgments}

We thank James Dohm and an anonymous reviewer for their comments and suggestions; also, we thank Matthias Grott for his comments on an early version of this work. J.R. was supported by a contract Ramón y Cajal co-financed from the Ministerio de Ciencia e Innovación of Spain and the Fondo Social Europeo (ESF). LPI contribution number LPI-001630.

\section{References}

Acuña, M.H. et al., 2001. Magnetic field of Mars: Summary of results from the aerobraking and mapping orbits. J. Geophys. Res. 106, 23403-23417.

Anderson, S., Grimm, R.E., 1998. Rift processes at the Valles Marineris, Mars: Constraints from gravity on necking and rate-depending strength evolution. J. Geophys. Res. 103, 11113-11124.

Baker, V.R., Maruyama, S., Dohm. J.M., 2007. Tharsis superplume and the geological evolution of early Mars. In: Yuen, D.A., Maruyama, S., Karato, S.-I., Windley, B.F. (Eds.), Superplumes: Beyond Plate Tectonics. Springer, Berlin, pp. 507-523.

Baratoux, D., Toplis, M.J., Monnereau, M., Gasnault, 0., 2011a. Thermal history of Mars inferred from orbital geochemistry of volcanic provinces. Nature 472 . 338-341.

Baratoux, D., Toplis, M.J., Monnereau, M., Gasnault, O., 2011b. Corrigendum: Thermal history of Mars inferred from orbital geochemistiy of volcanic provinces. Nature 475, 254

Beardsmore, G.R., Cull, J.P., 2001. Crustal Heat Flow: A Guide to Measurement and Modelling. Cambridge University Press, Cambridge, 324 pp.

Boynton, W.V. et aI., 2007. Concentration of $\mathrm{H}, \mathrm{Si}, \mathrm{Cl}, \mathrm{K}, \mathrm{Fe}$, and $\mathrm{Th}$ in the low and mid latitude regions of Mars. J. Geophys. Res. 112, E12S99. doi:10.1029/ 2007JE002887.

Burov, E.B., Diament, M., 1992. Flexure of the continental lithosphere with multilayered rheology. Geophys. J. Int. 109, 449-468.

Caristan, Y., 1982. The transitions from high temperature creep to fracture in Marylan diabase. J. Geophys. Res. 87, 6781-6790.

Chopra, P.N., Paterson, M.S., 1984. The role of water in the deformation of dunite. J. Geophys. Res, 89, 7861-7876.

Dohm, J.M., Tanaka, K.L., Hare, T.M., 2001. Geologic map of the Thaumasia region of Mars. USGS Misc. Inv. Ser. Map I-2650, scale 1:5000,000.

Dohm, J.M. et aI., 2009a. Claritas rise, Mars: Pre-Tharsis magmatism? J. Volcanol. Geotherm. Res. 185, 139-156.

Dohm, J.M. et al., 2009b. GRS Evidence and the possibility of paleooceans on Mars. Planet. Space Sci. 57, 664-684.

Dombard, A.J., Phillips, R.J., 2010. Viscoelastic finite-element simulations of the flexure under the north polar cap of Mars. Proc Lunar Planet. Sci. Conf. 41. Abstract 1865.

Fraeman, A.A., Korenaga, J., 2010. The influence of mantle melting on the evolution of Mars. Icarus 210, 43-57.

Frey, H.V., 2006. Impact constraints on, and a chronology for, major events in early Mars history. J. Geophys. Res. 111, E08S91. doi:10.1029/2005JE002449.

Grott, M., Breuer, D., 2009. Implications of large elastic thicknesses for the composition and current thermal state of Mars. Icarus 201, 540-548.

Grott, M., Breuer, D., 2010. On the spatial variability of the martian elastic lithosphere thickness: evidence for mantle plumes? J. Geophys. Res. 115. E03005, doi:10.1029/2009JE003456.

Grott, M., Hauber, E., Werner, S.C., Kronberg, P., Neukum, G., 2005. High heat flux on ancient Mars: Evidence from rift flank uplift at Coracis Fossae. Geophys. Res. Lett. 32, L21201. doi: 10.1029/2005GL023894.

Grott, M., Hauber, E., Werner, S.C., Kronberg, P., Neukum, G., 2007. Mechanical modelling of thrust faults in the Thaumasia region, Mars, and implications for the Noachian heat flux. Icarus 186, 517-526.

Hahn, B.C., McLennan, S.M., Klein, E.C., 2011. Martian surface heat production and crustal heat flow from Mars Odyssey gamma-ray spectrometry. Geophys. Res. Lett. doi:10.1029/2011GL047435, in press.

Halliday, A.N., Wänke, H., Birck, J.L., Clayton, R.N., 2001. The accretion, composition and early differentiation of Mars. Space Sci. Rev. 96, 197-230.

Hanna, J.C., Phillips, R.J., 2005. Hydrological modeling of the martian crust with application to the pressurization of aquifers. J. Geophys. Res. 110, E01004. doi:10.1029/2004JE002330.

Harmann, W.K. Neukum, G., 2001. Crateringchronology and the evolution of Mars. Space Sci. Rev. 96, 165-194.

Hauber, E., Broz, P., Jagert, F., Jodlowski, F., Platz, T., 2011. Very recent and widespread basaltic volcanism on Mars. Geophys. Res. Lett. 38, L.10201. doi:10.1029/ 2011GL047310.

Hauck, S.A., Phillips, R.J., 2002. Thermal and crustal evolution of Mars. J. Geophys. Res. 107, 5052. doi: 10.1029/2001JE001801.
. et al, 2001. Geological processes and evolution. Space Sci. Rev. 96, 263 292

Hofmeister, A.M., 1999. Mantle values of thermal conductivity and the geotherm from phonon lifetimes. Science 283, 1699-1706.

Jaupart, C., Labrosse, S., Mareschal, J.C., 2007. Temperatures, heat and energy in the mantle of the Earth. In: Bercovici, S. (Ed.). Treatise on Geophysics: Mantle Dynamics, vol. 7. Elsevier, Amsterdam, pp. 253-303.

Kiefer,W.S., 2004. Gravity evidence for a extinct magma chamber beneath Syris Major, Marts: A look at the magmatic plumbing system. Earth Planet. Sci. lett $222,349-361$

Kiefer, W.S., Li, Q. 2009. Mantle convection controls the observed lateral variations in lithospheric thickess on present-day Mars. Geophys. Res. lett. doi:10.1029/ 2009 GL.039827.

Kieffer, H.H. et aI., 1977. Thermal and albedo mapping of Mars during the Viking primary mission. J. Geophys. Res. 82, 4249-4291.

Korenaga, J., 2008. Urey ratio and the structure and evolution of Earth's mantle. Rev. Geophys. 46, 1-32.

Kronberg, P. et aI., 2007. Acheron Fossae, Mars: Tectonic rifting, volcanism, and implications for lithospheric thickness. J. Geophys. Res. 112, E04005 doi: 10.1029/2006JE002780.

Kumar, R.R., Gordon, R.G., 2009. Horizontal thermal contraction of oceanic lithosphere: The ultimate limit to the rigid plate approximation. J. Geophys. Res. 114, B01403. doi: 10.1029/2007JB005473.

McGovern, P.J., Schubert, G., 1989. Thermal evolution of the Earth: Effects of volatile exchange between atmosphere and interior. Earth Planet. Sci. Lett. 96, 27-37.

McGovern, P.J. et aI., 2002. Localized gravity/topography admittance and correlation spectra on Mars: Implications for regional and global evolution. J. Geophys. Res. 107, 5136. doi:10.1029/2002 JE001854.

McGovern, P.J. et aI., 2004. Correction to localized gravity/topography admittance and correlation spectra on Mars: Implications for regional and global evolution. J. Geophys. Res. 109, E07007. doi:10.1029/2004JE002286.

McKenzie, D., Jackson, J., Priestley, K, 2005. Thermal structure of oceanic and continental lithosphere. Earth Planet. Sci. Lett. 233, 337-349.

McNutt, M.K, 1984. Lithospheric flexure and thermal anomalies.J. Geophys. Res. 89. $11180-11194$.

McNutt, M.K, Diament, M., Kogan, M.G., 1988. Variations of elastic plate thiclness at continental thrust belts. J. Geophys. Res. 93, 8825-8838.

Montesi, L.G.J.,Zuber, M.T., 2003. Clues to the lithospheric structure of martian from winkle ridge sets and localization instability. J. Geophys. Res. 108, 5048. doi: 10.1029/2002JE001974

Nahm, A.L., Schultz, R.A., 2011. Magnitude of global contraction on Mars from analysis of surface faults: Implications for martian thermal history. Icarus 211 , $389-400$.

Neumann, G.A. et aI., 2004. The crustal structure of Mars from gravity and topography. J. Geophys. Res. 109, E08002. doi:10.1029/2004JE002262.

Neumann, G.A., Lemoine, F.G., Smith, D.E., Zuber, M.T., 2008. Marscrust3-A crustal thickness inversion from recent MRO gravity solutions. Proc. Lunar Planet. Sci. Conf. 39. Abstract 2167.

Nimmo, F., 2002. Admittance estimates of mean crustal thickness and density at the martian hemispheric dichotomy. J. Geophys. Res. 107, 5117. doi:10.1029/ 2000JE001488.

Nimmo, F., Stevenson, D. J., 2000. Influence of early plate vectonics on the thermal evolution and magnetic field of Mars. J. Geophys. Res. 105, 11969-11979.

Parmentier, E.M., Zuber, M.T., 2007. Early evolution of Mars with mantle compositional swatification or hydrothermal crustal cooling. J. Geophys. Res. 112, E02007. doi:10.1029/2005JE002626.

Petrenko, V.F., Whitworth, R.W., 1999. Physics of Ice. Oxford Univ. Press, Oxford, 366pp.

Phillips, RJ. et aL, 2008. Mars north polar deposits: Stratigraphy, age, and geodynamical response. Science $320,1182-1185$.

Plaut, J.J. et al., 2007. Subsurface radar sounding of the south polar layered deposits of Mars. Science 316, 92-95.

Ranalli, G., 1994. Nonlinear flexure and equivalent mechanical thickness of the lithosphere. Tectonophysics 240, 107-114.

Ranalli, G., 1997. Rheology of the lithosphere in space and time. Geol. Soc. Spec. Pub. $121,19-37$

Ritzer, J.A., Hauck, S.A., 2009. Lithospheric structure and tectonic at Isidis Planitia, Mars. Icarus 201, 528-539.

Ruiz, J., 2009. The very early thermal state of Terra Cimmeria: Implications for magnetic carriers in the crust of Mars. Icarus 203, 454-459.

Ruiz, J., Tejero, R., 2000. Heat flows through the ice lithosphere of Europa. J. Geophys. Res. 105, 23283-23289.

Ruiz.J., McGovern, P.J., Tejero, R., 2006a. The early thermal and magnetic state of the cratered highlands of Mars. Earth Planet. Sci. Lett. 241, 2-10.

Ruiz, J., Tejero, R., McGovern, P.J., 2006b. Evidence for a differentiated crust at Solis Planum, Mars, from Iithospheric strength and heat flow. Icarus 180, 308-313.

Ruiz, I., Gómez-Ortiz, D., Tejero, R., 2006c. Effective elastic thicknesses of the lithosphere in the Central Iberian Peninsula from heat flow: Implications for the rheology of the continental lithospheric mantle. J. Geodyn. 41, 500-509.

Ruiz, J. et al., 2008. Ancient heat flow, crustal thickness, and lithospheric mantle rheology in the Amenthes region, Mars. Earth Planet. Sci. Iett. 270, 1-12.

Ruiz,J., Williams, J.P., Dohm.J.M., Fernández, C.z López, V., 2009. Ancient heat flows and crustal thickess at Warrego rise, Thaumasia Highlands, Mars: Implications for a stratified crust. Icarus 203, 47-57.

Ruiz, J., López, V., Dohm, J.M., 2010. The present-day thermal state of Mars. Icarus 207, 631-637. 
Sandu, C., Lenardic, A., McGovern, P., 2011. The effects of volatile cycling on planetary thermal evolution. J. Geophys. Res., submitted for publication.

Schultz, R.A., Watters, T.R., 2001. Forward mechanical modeling of the Amenthes Rupes thrust fault on Mars. Geophys. Res. Lett. 28, 4659-4662.

Shuster, D.L., Weiss, B.P., 2005. Martian surface paleotemperatures from thermochronology of meteorites. Science 309, 594-597.

Sleep, N.H., 1994. Martian plate tectonics. J. Geophys. Res. 99, 5639-5655.

Solomon, S.C., Head, J.W., 1990. Heterogeneities in the thickness of the elastic lithosphere of Mars: Constraints on heat flow and internal dynamics. J Geophys. Res. 95, 11073-11083.

Tanaka, K.L., 1986. The stratigraphy of Mars. J. Geophys. Res. 91, E139-E158.

Taylor, S.R., McLennan, S.M., 2009. Planetary Crusts: Their Composition, Origin and Evolution. Cambridge Univ. Press, Cambridge.

Taylor, G.J. et al., 2006. Bulk composition and early differentiation of Mars. J. Geophys. Res. 111, E03S10. doi:10.1029/2005JE002645 (Printed 112 (E3), 2007)

Tesauro, M., Kaban, M.K., Cloetingh, S.A.P.L., Hardebol, N.J., Beekman, F., 2007. 3D strength and gravity anomalies of the European lithosphere. Earth Planet. Sci. Lett. 263, 56-73.

Turcotte, D.L., Schubert, G., 2002. Geodynamics, second ed. Cambridge Univ. Press, Cambridge, 456pp.
Van Schmus, W.R., 1995. Natural radioactivity of the crust and mantle. In: Ahrens, T.J. (Ed.), Global Earth Physics: A Handbook of Physical constants. AGU Reference Shelf 1. American Geophysical Union, Washington, DC, pp. 283-291.

Wänke, H., Dreibus, G., 1988. Chemical composition and accretion history of terrestrial planets. Philos. Trans. Roy. Soc. London: Ser. A 325, 545-557.

Watters, T.R. et al., 2006. MARSIS radar sounder evidence of buried basins in the northern lowlands of Mars. Nature 444, 905-908.

Watts, A.B., Burov, E.B., 2003. Lithospheric strength and its relation to the elastic and seismogenetic layer thickness. Earth Planet. Sci. Lett. 213, 113-131.

Wieczorek, M.A., 2008. Constraints on the composition of the martian south polar cap from gravity and topography. lcarus 196, 506-517.

Williams, J.-P., Nimmo, F., 2004. Thermal evolution of the martian core: Implications for an early dynamo. Geology 32, 97-100.

Yoder, C.F., Konopliv, A.S., Yuan, D.N., Standish, E.M., Folkner, W.M., 2003. Fluid core size of Mars from detection of the solar core. Science 300, 299-303.

Zhao, Y.-H., Zimmerman, M.E., Kohlstedt, D.L., 2009. Effect of iron content on the creep behavior of olivine: 1. Anhydrous conditions. Earth Planet. Sci. Lett. 287, 229-240.

Zuber, M.T. et al., 2000. Internal swucture and early thermal evolution of Mars from Mars Global Surveyor. Science 287, 1788-1793. 